\title{
Teaching Discussion of the Organic Chemistry Curriculum for Environmental Engineering Major
}

\author{
Weijian Cai \\ School of Food Science and Biotechnology, Zhejiang Gongshang University, \\ Hangzhou 310018, China \\ E-mail address: li169@sina.com; caiwj158@sina.com
}

Keywords: Environmental engineering major; Organic Chemistry; Teaching discussion; Curriculum

\begin{abstract}
Organic Chemistry is one of the important elementary courses of environmental engineering major. According to the major requirements, we take targeted steps to teach students in accordance of their aptitude emphasize on communication, reform teaching methods and properly use various kinds of teaching and experimental means. In this way, we arouse students' interesting of learning Organic Chemistry and improve the teaching effects and quality.
\end{abstract}

\section{Introduction}

Organic Chemistry is one of the important elementary courses of environmental engineering major in colleges and universities and also an important part of the environmental engineering students' knowledge chain. The teaching aim of Organic Chemistry is not only of making students acquire the knowledge of Organic Chemistry, but also of cultivating students' scientific thinking methods and rigorous science attitudes. Therefore, the teaching effect of Organic Chemistry directly influences students' learning quality of further courses [1].

Originating in the end of the 1970s, environmental engineering major is a new-emerging and comprehensive discipline. By using theories and methods of environmental science, engineering science and other related disciplines, it is a promising discipline that makes researches of protecting and making reasonable use of natural resources and controls, prevents and cures environmental pollutions in order to improve the quality of environment and make people live a healthy and comfortable life. Chemistry is one of the important related disciplines. What's more, Organic Chemistry is an indispensable elementary course in the curriculum system in colleges and universities which have environmental engineering major.

This paper makes beneficial discussion of cultivating innovative and high-quality applied talents, by combining the characteristic teaching which reforms the Organic Chemistry during the discipline construction in environmental engineering discipline of Zhejiang Gongshang University.

\section{Teaching Reform and Discussion}

\subsection{Leaning the Overall Situation and Teaching Students in Accordance to Their Aptitude}

At present, the universal problems of Organic Chemistry teaching in environmental engineering major are as follows: the teaching hours are largely reduced. Most professional teaching hours are less than 50, while the teaching content isn't reduced basically. So the phenomena appears that teachers can't teach in depth and students can't learn proficiently[2]. There are lots of equations, reaction conditions and influence factors in the course Organic Chemistry. At the same time, it is strongly theoretical and the reaction mechanism is abstract and hard to remember. These factors make students feel bored, dull and confused and lower their learning interests so the learning results are universally not very ideal. What's more, when our students are in junior grade, they can't understand the function of organic chemistry in their own major very well or integrate the basic knowledge of Organic Chemistry into their own major so they lack learning motivation. In the aspect of teaching, there are contradictions between traditional and modern teaching methods. Therefore, how to make students learn more knowledge of Organic Chemistry in limited time, improve their comprehensive qualities and innovative ability and lay a solid foundation for future 
academic study and development are the requirement of "Organic Chemistry" teaching that we must meet.

According to the social need of the talents of environmental engineering, we should emphasize on cultivating students' comprehensive qualities, optimize the teaching content of the course and "try our best to allocate class hour reasonably and make the teaching content in the scientific frontier" [3-4]. In the aspect of teaching content, because students' major is environmental engineering and in the future their processing objects are the environmental pollutants, especially the organic pollutants; on this basis we should boldly reform the teaching content. While teaching, we should add the teaching content such as the origin and the damage of the environmental pollutants and so on. We should adapt suitable methods of organic chemistry to the corresponding environmental pollutants. In this way, our students can understand the environmental pollutants deeply and master the analytical methods as well. It is called kill two birds with one stone which can get good results. Through reasonable optimization and adjustment of teaching content, we motivate students' interests of learning Organic Chemistry, cultivate their innovation and improve their comprehensive qualities. What's more, combining the teaching content, we strengthen the relationship between the course and the major and integrate some newest research and technological achievements which are invented in the production and scientific research at home and abroad into the teaching content. At the same time, we encourage students pay attention to social hot spots, such as water eutrophication, the blackened and rotten water, POPs pollutants, and residual pesticide in vegetables and so on. We strive to make students learn the trends of frontier knowledge in order to increase their learning interests and subjective initiative and make them seek knowledge on their own.

\subsection{Paying Attention to Communication and Reforming Teaching Methods}

Improving the quality of classroom teaching is an important way to realize the purpose of "imparting knowledge and educating people". Classroom teaching is the basic form of realizing teaching aims and accomplishing teaching tasks and is also the major place of "bilateral activities" and "two-way communication" for teachers and students. The classroom teaching adapts various and flexible methods such as "heuristic method", "research method", "guide method", "discussion method", "interactive communication method", "comprehensive goals method" and so on[5-6]. It also insists on linking theory with practice, intensive teaching and practicing frequently. It pays attention to not only all the students, but also the individual development of students. The teaching practice proves that while teaching, we should set the goal of cultivating students' innovative qualities, emphasize on teaching students in accordance of their aptitude, reform teaching technologies and innovate teaching modes. These are keys to cultivate innovative talents. In the reform of classroom teaching of Organic Chemistry, we should lay emphasis on the integrated and case teaching methods and combine academic knowledge with basic knowledge of chemistry. We should also teach the cases of the practical analysis technologies in the class and use the methods of students' analysis and discussion to increase the class interactivity and students' initiative. These methods are very popular among students. For example, only looking at the planate and still illustrations in the textbook is very difficult to understand the configuration changes of stereoscopic organic chemical molecules, because they generate in the three-dimensional space. If we use a model of three-dimensional molecular structure to demonstrate and materialize the abstract content, it can increase the interest of the class learning and make students understand the stereoscopic molecular structure deeply. At the same time, we also train students' ability of spatial thinking.

\subsection{Making Elaborate Courseware and Improving the Teaching Results}

Because of the expansion of enrollment scale and the limit of teaching resources, as a basic course, Organic Chemistry is usually taught in a big-scale class which consists of two or three natural classes. Because students seat in the back of the class and can't see the blackboard-writing clearly, the traditional teaching form of using blackboards and chalk has seriously influenced the teaching results in the large and crowded class. Therefore, it is necessary to use multimedia, which it ensures that students can see and hear clearly. It is the foundation of teaching quality of Organic Chemistry. Multimedia teaching has many advantages that are superior to traditional teaching, but 
there are also a lot of problems. The biggest problem is that it has large amount of information and the teaching pace is too fast. It causes that some students can't follow teacher's thinking and drop lots of precious information [7-8]. Students, especially the freshmen, think the knowledge they accept is not consistent, because they are not accustomed to the teaching methods of fast pace and large amount of information which make their learning more difficult. Thus, when we are making courseware and teaching, we should pay attention to control the speed of demonstration and make the visual information keep pace with teacher's thinking, students' acceptance and speed of taking notes to the best our ability. We should also give students time to take notes and thinking to help them master and understand the knowledge in time. Then, some courseware is too formalistic or showy. The formalistic one, because of lacking novelty, makes students produce the visual fatigue and feel bored, while the showy one distracts students' attention and influences their thinking. Therefore, according to the requirements of the course, it is necessary to make a set of elaborate and practical courseware. Based on many years' experience, we find that the multimedia courseware of sober background color matching with clear words and simple and marked layout is the most popular. In the aspect of content, it is essential to demonstrate the abstract content which is hard to understand by using slow animation showing such as the hybridization of atom, addition reaction, substitution reaction, SN1 and SN2 reaction, the process of configuration transition and orientation effect and so on. In this way, students can understand the reaction process more intuitively and master the knowledge more deeply and comprehensively. We can use simple formulas to describe other reaction process. It is easy for students to understand all kinds of material structures by using more vivid and intuitive models and pictures.

\subsection{Summarizing and Concluding the Knowledge Points Properly for the Sake of Memorizing}

After finishing each chapter, we ask students to conclude the main points of the chapter according to the relationship between structure and property. At the same time, according to the past teaching experience, the teacher concludes the laws for students to memorize. For example, by comparing, we find the common ground, point out differences and make several knowledge points into a line to lessen students' burden of memory, facilitate their understanding and broaden their scope of knowledge. For example, by analyzing and comparing the differences of counterattack reagents and reaction intermediates (in Fig.1), we point out the differences between the electrophilic addition of alkyne and nucleophilic addition of carbonyl compound to help students master them easily.

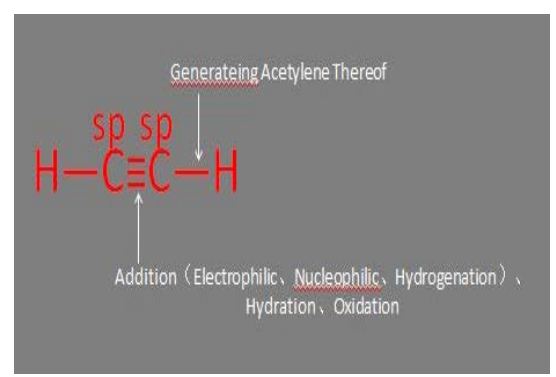

Fig.1. The structure and chemical property of alkyne

\subsection{Designing Experimental Projects According to the Requirements of the Major}

Organic Chemistry is a strong practicing discipline. The experimental course of Organic Chemistry can help students to understand and master the fundamental theories and reactions of Organic Chemistry from the theoretical level to practical level. It is also the essential link and effective ways of helping students to learn the theoretical knowledge of Organic Chemistry well. Good experimental teaching methods can motivate students' passion of learning and exploration [9]. In order to ensure the cultivation of professional quality of students, we reform boldly in the experimental projects of Organic Chemistry. It not only covers all the major knowledge Organic Chemistry, but also links all the experimental projects with the major. When arranging experiments, we reduce the use of poisonous drugs or the emission of toxic wastes. For example, we eliminate the $\mathrm{C}_{6} \mathrm{H}_{10}$ preparation experiment, because it produces large amount of white smoke and seriously pollutes the environment. For example, the $\mathrm{C}_{6} \mathrm{H}_{10} \mathrm{O}_{4}$ preparation experiment uses $\mathrm{KM}_{\mathrm{n}} \mathrm{O}_{4}$ oxidation 
method to replace the $\mathrm{HNO}_{3}$ oxidation method. In this way, we avoid producing large amount of poisonous $\mathrm{NO}$ and the strong corrosion by using $\mathrm{HNO}_{3}$., improve the safety of the experiment and reduce the pollution to the environment. After finishing the experiment, we recycle and reuse the waste fluid, residue and bottles and forbid students to pour the organic solvents and poisonous drugs into the pool. We ask students to recycle the wastes according to their types and make students feel that their behaviors have important influence to the environment. The products we get in the synthetic experiment must be recycled and keep them for the next students' training. In this way, we keep the labs no pollutes and form a virtuous cycle of products chain. In the end, we train students' green chemical awareness of reducing pollution and zero discharge and strengthen their responsibilities of protecting the environment.

In addition, we can arrange some open experiments by combing our teachers' scientific research projects. The labs can be open to students in a particular period. For example, if the research group mainly works on the environmental solid wastes treatment and resource, the teacher can ask students to engage in the research project of aerobic fermentation in urban sludge. Through the involvement of the project and the understanding of professional knowledge, we can train their ability of independent thinking and solving problems. By using the targeted experiment project, we can make dynamic integration between the knowledge of organic chemistry and professional practice, improve the results of theory teaching and increase their ability of applying the knowledge to practical use.

\section{Conclusions}

Because of the increasing requirements of the talents' quality in environmental engineering major, we make innovative teaching reforms in the traditional Organic Chemistry course based on the analysis of the current teaching situation. Emphasizing on the effective combination of chemical and professional knowledge, we make students not only learn the basic knowledge of organic chemistry, but also produce strong interest in their major. It provides some successful experience for the teaching reform of Organic Chemistry in universities and colleges' environmental engineering major.

\section{References}

[1] L. Chen, X. Yan, and H. Zhang, "The Research and practice of teaching reform in Organic Chemistry for chemical engineering specialty," Guangdong Chemical Industry, vol. 287, pp.268-269, 2014.

[2] H.X. Huang, "Teaching status and Reform in Organic Chemistry for technological University," Science and Technology Consulting Herald, 14, pp.169, 2011.

[3] J.Q. Long, B.F.Shi, "Innovative teaching methods to improve the effect of organic chemistry teaching,” Scientific and Technological Information, 13, pp.214, 2011.

[4] H. Chen, R. Liao, W. Hu, "Teaching reform and practice on the course of organic chemistry," Chinese Geological Education, 4, pp.109-111, 2010.

[5] L.H. Meng, "The investigation and analysis of present situation of the chemistry normal students’ scientific inquiry ability training,” Dongbei Normal University, 2012.

[6] S. Chen, P. Liu, “Application of inquiry teaching in organic chemistry teaching," China Science and Technology Information, 11, pp.221-222, 2012.

[7] F. Jia, "Analysis for training of science inquiry ability in the teaching of organic chemistry in university,” Journal of chengdu institute of education, 7, pp.236, 2011.

[8] J. Yang, “Chemical education specialty in students' science inquiry ability training," Hebei Normal University, 2012.

[9] L. Mo, "Train the ability of scientific inquiry to improve the quality of chemistry teaching practice research,” Tianjin Normal University, 2012. 